\title{
Breve síntesis sobre la introducción de nuevo armamento en Egipto durante la dinastía XVIII
}

\author{
Javier Martínez Babón *
}

\begin{abstract}
RESUMEN SUMMARY
The traditional Egyptology

emphasises that new weapons were introduced in Egypt during the Hyksos Period. If we studied the sources, we could conclude that, in their last phase, the Hyksos introduced horses and chariots, swords and daggers with inlaid handles, and composite bows. Other weapons, traditionally associated to the Hyksos, like armours, helmets and sickleswords, arrived to Egypt during the first phase of the XVIIIth Dynasty, when Egypt conquered the territories of Syria-Palestine. In spite of the new technology, the Egyptian Army kept on using weapons of great tradition, as the axe.
\end{abstract}

* Escuela de Egiptología de la Fundación Arqueológica Clos. 
La historia del armamento egipcio ha sido un tema poco estudiado por la egiptología internacional. La evidencia más clara de ello la tenemos en el hecho de que todavía hoy tienen plena vigencia muchos de los postulados de la obra específica que escribió Wolf en el año $1926{ }^{1}$. Al lado de este gran libro podemos citar importantes referencias a las armas egipcias en los clásicos de F. Petrie ${ }^{2}, \mathrm{H}$. Bonnet ${ }^{3} \mathrm{o}$ de $Y$. Yadin ${ }^{4}$. Estas obras, de consulta obligatoria para cualquier investigador que pretenda trabajar sobre armamento antiguo, se complementan con algunos trabajos monográficos ${ }^{5} \mathrm{y}$ artículos especializados. Curiosamente, otros ámbitos culturales contemporáneos, como las antiguas civilizaciones del Próximo Oriente asiático o el Egeo, poseen una extensa bibliografía sobre objetos bélicos que, en ocasiones, incluye armas egipcias para establecer comparaciones.

\section{ANTECEDENTES HISTÓRICOS}

Desde la época de la unificación hasta principios del Segundo Período Intermedio (ca. 3050-1785 a.C.) Egipto pasó por conflictos militares internos, como las sangrientas guerras civiles del Primer Período Intermedio, y se enfrentó puntualmente contra bandas de libios, nubios y asiáticos. La carencia de un enemigo exterior poderoso no incentivó la necesidad de unas fuerzas armadas profesionales y tampoco propició el interés por una tecnología armamentística innovadora. Ejército y armas formaban parte de una visión geopolítica defensiva que queda patente en las cadenas de fortalezas construidas en las inmediaciones de la segunda catarata durante el Imperio Medio ${ }^{6}$.

Die Bewaffnung des altägyptischen Heeres. Leipzig, 1926.

Tools and Weapons. Londres, 1917.

Die Waffen der Völker des alten Orients. Leipzig, 1926.

The Art of Warfare in Biblical Lands. Londres, 1963.

Amplias monografías destacables son: KüHNERT-EgGeBrecht, E.: Die Axt als Waffe und Werkzeug im Alten Ägypten. MÄS 15 (1969); MACLEOD, W.: Composite Bows from the Tomb of Tut'ankhamun. TTS Ill. Oxford, 1970; Ibid.: Self Bows and other Archery Tackle from the Tomb of Tut'ankhamun. TTS IV. Oxford, 1982; DAVIES, W. V: Catalogue of Egyptian Antiquities VII. Tools and Weapons, Axes. Londres, 1987; MÜLLER, H. W.: Der Waffenfund von Balata-Sichem und die Sichelschwerter. BAW 97 (1987). Estas obras se completan con trabajos reiacionados indirectamente con armamento, como informes arqueológicos que incluyen objetos bélicos, y artículos especializados, algunos de los cuales serán citados en el transcurso de estas líneas.

${ }_{6}$ Una buena aproximación a las fortalezas egipcias se encuentra en A.W. LAWRENCE (Ancient Egyptian Fortifications. JEA 51 (1965): 69-94). 
Durante más de un milenio los soldados egipcios combatieron con bastones, a los cuales se les añadiría una hoja metálica a principios del Primer Período Intermedio; mazas de cabeza pétrea, abandonadas progresivamente para la guerra en el transcurso de las primeras dinastías aunque tendrían un papel simbólico a lo largo de toda la historia de Egipto "; hachas, elaboradas con hojas de diferentes formas, inicialmente de piedra y posteriormente de metal; puñales con hojas de obsidiana o metálicas que se estrechaban en un extremo para ser introducidas a una empuñadura de madera; lanzas, venablos y flechas de caña o vara con puntas de sílex y, ocasionalmente, de metal; hondas; arcos, fabricados con una vara, generalmente de acacia, o con dos astas de íbice unidas, y escudos constituidos por una plancha de madera forrada con piel de animal que portaban asideros rígidos horizontales o verticales. Escenas bélicas esculpidas o pintadas en tumbas privadas (fig.1), los célebres frisos de los sarcófagos medioimperiales, algunos textos y las variadas piezas, halladas en mejor o peor estado de conservación, demuestran la escasa evolución de las armas egipcias. Únicamente podemos subrayar un aspecto innovador y que, inicialmente, no tenía relación directa con el arte de la guerra: el progresivo cambio de metales. A principios de la historia egipcia se extendió el uso del cobre y, a finales del Primer Período Intermedio o comienzos del Imperio Medio, se fue implantando el bronce ${ }^{8}$.

La grave crisis política, con secesiones incluidas, acaecida a finales del Imperio Medio, condujo al oscuro Segundo Período Intermedio

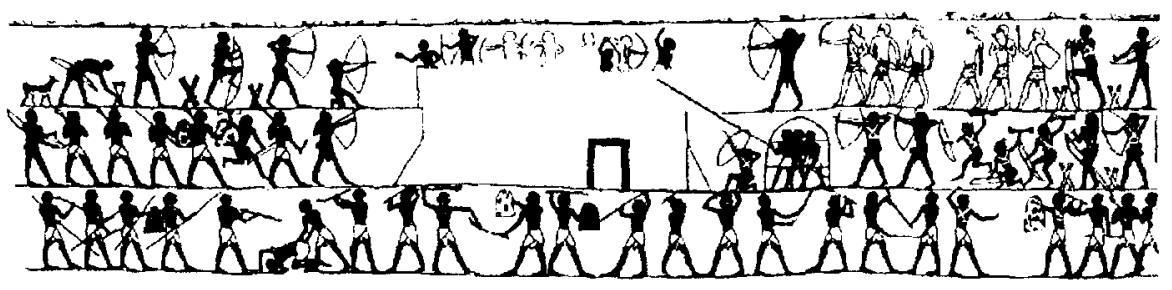

Figura 1. Asalto a una fortaleza. Tumba del nomarca Bakett III en Beni Hasan. P. NEWBERRY, Beni Hasan. Vol. II, Londres, 1893: lám. 5.

\footnotetext{
El uso generalizado de la clásica maza piriforme en el campo de batalla desapareció ya durante las primeras dinastías de la historia egipcia (WOLF, op. cit.: 5).

8 Sobre el bronce en Egipto se puede consultar la excelente obra de A. LUCAS (Ancient Egyptian Materials and Industries. Londres, 1989 (4. ${ }^{\text { Ed.) }}$ : 217-224.
} 
(ca. 1785-1552 a.C.). La irrupción de los hicsos por el nordeste, a mediados del siglo XVII a.C., y el avance de los kuschitas de Kerma desde el sur obligarían a un repliegue de resistentes egipcios hacia los dominios de la ciudad de Tebas. De nada habían servido las fortalezas fronterizas o los ejércitos de milicianos nacionales y auxiliares nubios, mal armados, frente a tropas hicsas mejor organizadas o guerreros kuschitas motivados. Los monarcas tebanos, traumatizados por las invasiones y sometidos a una constante presión geopolítica, se vieron obligados a desarrollar una mentalidad militarista sin precedentes en la historia egipcia. A finales de este período, Tebas poseería unos gobernantes que marchaban al frente de sus tropas, como evidencia la cabeza de la momia de Sequenere Taa con sus cinco heridas mortales $^{9}$, y un ejército profesionalizado, como indica el preámbulo de la célebre biografía del oficial Ahmose, hijo de Ebana, al referir que él ocupó la plaza de su padre en las fuerzas armadas (Urk.IV: 2).

Una idea ampliamente aceptada apunta hacia la superioridad armamentística hicsa como uno de los factores que provocaron el hundimiento defensivo egipcio. La historiografía tradicional postula que estos guerreros asiáticos entraron en el país del Nilo y se mantuvieron en el poder durante algo más de un siglo gracias a un armamento moderno para aquella época, entre el que sobresalían los carros de guerra ligeros tirados por dos caballos, los arcos compuestos, las protecciones corporales, así como los puñales y espadas curvas fabricados en una sola pieza de bronce ${ }^{10}$. Ante semejante aseveración debemos tener en cuenta dos consideraciones:

9 Sequenere murió a causa de heridas provocadas por armas asiáticas y egipcias ( $M$. BIETAK/E. Strouhal, Die Todesumstände des Pharaos Seqenenre (17. Dynastie). ANMW 78 (1974): 44-51.

10 Algunos de los investigadores que tradicionalmente han defendido la teoría de los avances armamentísticos portados por los hicsos a Egipto, generalmente sin especificar el momento, son: WOLF (op. cit.: 43, 88) destaca la introducción de puñales fundidos en una pieza de bronce y carros de guerra tirados por caballos; H. E. WINLOCK (The Rise and Fall of the Middle Kingdom at Thebes. Nueva York, 1947: 152-163) subraya la entrada en Egipto de carros de guerra, arcos compuestos, puntas metálicas, nuevos modelos de puñales y espadas, y espadas curvas; T. SÄvE-SödERBERGH (The Hyksos Rule in Egypt. JEA 37 (1951): 61) incluye, como novedades, los carros de guerra, nuevos tipos de puñales y espadas, arcos compuestos, y concluye con unos significativos puntos suspensivos; J. Von BECKERATH (Untersuchungen zur politischen Geschichte der Zweiten Zwischenzeit in Ägypten. ÄF 23 (1964): 120) da por válidos los postulados de WINLOCK; H.W. MüLLER (op. cit.: 129) menciona, como novedades hicsas, el carro de guerra, el arco compuesto, el casco metálico y la cota. 
1. No hay constancia de que los hicsos conquistaran Egipto gracias a un armamentc superior. De hecho, las excavaciones austriacas en Tell el-Dab'a, la antigua Avaris, han reportado unas armas del BM asiático que no otorgaban una manifiesta superioridad a sus poseedores ${ }^{11}$. Sí parece evidente, como se verá más adelante, que algunas armas fueron incorporadas a los arsenales de los asiáticos cuando éstos ya gobernaban en buena parte del país del Nilo.

2. Los tebanos que iniciaron la guerra de liberación contra los asiáticos no se esforzaron demasiado en adoptar nueva tecnología militar. Sus armas eran similares a las de sus antecesores del Imperio Medio y únicamente se aprecian dos presuntos intentos de mejora armamentística: la progresiva implantación del modelo clásico de hoja de hacha, con filo convexo y lados cóncavos ${ }^{12}$ (fig.2), y una curiosa modalidad de espada recta que tendría escaso resultado ${ }^{13}$ (fig.3).

A finales del Segundo Período Intermedio, cuando los tebanos Sequenere y Kamose se enfrentaron contra las huestes del hicso Apofis, ya se observa una clara diferencia armamentística entre ambos bandos: por parte hicsa está documentada la existencia de caballos en la Segunda Estela de Kamose, se han encontrado puñales y espadas

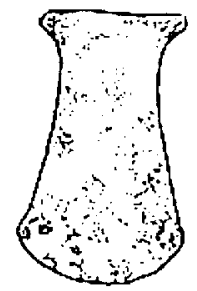

Figura 2. Hoja de hacha hallada en Buhen (din. XII-XIII). Copiada a partir de una foto en WOLF (op. cit.: lám. 11).

1 Las excavaciones en Tell el-Dab'a han sido dirigidas durante muchos por M. BIETAK y las armas encontradas en tumbas aparecen en muchas de sus publicaciones. Ver, por ejemplo, en: M. BIETAK/E. StRouHAL, op. cit.: láms. 2-4.

12 Durante muchos años se pensó que el orígen de este tipo de hacha se remontaba a la dinastía XII (PETRIE, op. cit.: 8ss; WolF, op. cit.: 36-37). Trabajos más recientes, como el de KÜHNERT-EGGEBRECHT (op. cit.: 29-30), sitúan las primeras piezas en la dinastía XIII.

13 La primera, hallada en la tumba de la reina Aahotep, presentó dudas sobre la posibilidad de que fuera una larga punta de lanza (WoLF, op. cit.: 76) hasta que fue encontrada en una tumba de Tebas oeste la segunda (WINLOCK, Op. cit.: lám. 28). 
cortas fundidos en una sola pieza de bronce ${ }^{14}$ (fig. 4), y, por referencias indirectas, podemos destacar el probable uso del arco compuesto ${ }^{15}$. Sin embargo, los asiáticos, mejor armados, serían incapaces de resistir el empuje de los tebanos. Semejante paradoja tiene una fácil explicación: las fuentes de Kamose explican que los tebanos centraron su estrategia militar en ataques relámpago contra localidades ribereñas

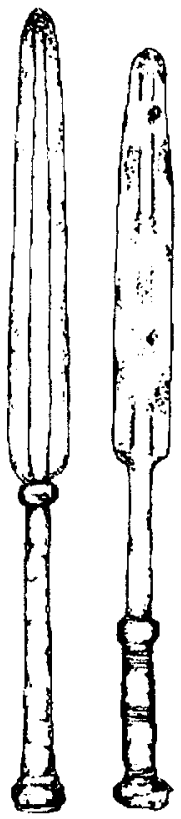

Figura 3. Espadas tebanas copiadas a partir de fotos en WOLF (op. cit:: lám. 14) y WINLOCK (op. cit.: lám. 28).
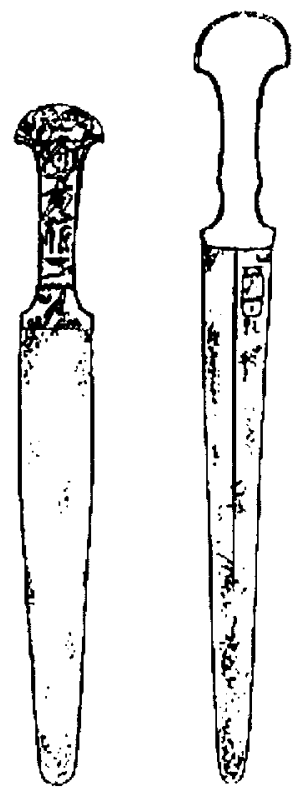

Figura 4. Puñal $(35,2$ cmts) y espada $(40,3$ cmts) que portan nombres de Apofis. Dibujos copiados a partir de fotos que aparecen en los artículos de DARESSY y DAWSON.

14 La primera pieza, de hoja plana, conserva dos nombres de Apofis en la empuñadura (G. DARESSY, Un poignard du temps des rois pasteurs. ASAE 7 (1906): 115-120), mientras que la segunda, con nervatura recorriendo la totalidad de la hoja, porta uno de los nombres de Apofis en la hoja (W.R. DAwson, A Bronze Dagger of the Hyksos Period. JEA 11 (1925): 216-217).

15 Aunque no se han encontrado arcos compuestos asociados a los hicsos, tenemos evidencias de que a principios de la dinastía XVIII, como se menciona más abajo, ya eran utilizados por las tropas egipcias, con lo cual podemos concluir que los asiáticos eran portadores de semejantes armas. 
o puntos del desierto ${ }^{16}$. Este sistema de combate, similar al que habían usado sus ancestros durante las guerras del Primer Período Intermedio, neutralizó la superioridad tecnológica asiática y permitió un notable avance de fronteras hacia el norte. Asimismo, Kamose reconquistaría a los kuschitas la zona comprendida entre la primera y segunda cataratas.

\section{PRIMERA FASE DE LA DINASTIA XVIII (AHMOSE-AMENHOTEP II): LA INTRODUCCIÓN DE NUEVO ARMAMENTO Y LA MEJORA TECNOLÓGICA}

Cuando Ahmose (ca. 1552-1527 a.C.), hermano del anterior y primer monarca de la dinastía XVIII, subió al trono de Tebas, los hicsos controlaban todavía la totalidad del delta egipcio. En el transcurso de su gobierno, este faraón lograría acabar con el dominio asiático e iniciaría una primera expansión política hacia el sur de Palestina ${ }^{17}$. Esta directriz, claramente militarista, tendria amplia continuidad en los programas políticos de algunos de sus sucesores: Thutmés I (ca. 15061494 a.C.) destruyó el reino de Kusch, efectuó una demostración de fuerza en Asia ante sirios y mitannios que concluyó con el levantamiento de una estela en la ribera del Éufrates (Urk.IV: 697) y ordenó la construcción de grandes acuartelamientos militares en Memfis ${ }^{18}$, en tanto que Hatschepsut (ca. 1490-1468 a.C.) comandó personalmente una de las expediciones que, bajo su gobierno, se llevaron a término contra rebeldes kuschitas ${ }^{19}$. El progresivo protagonismo internacional

16 El sistema de combate tebano queda recogido en las fuentes conservadas de Kamose, sobre todo en la célebre Segunda Estela. Una buena traducción de la misma fue efectuada por L. HABACHI (The Second Stela of Kamose and His Struggle Against the Hyksos. DAI (Cairo) 8. Glückstadt, 1972).

17 Tenemos evidencias de una primera expansión militar hacia Asia en la biografias de los militares Ahmose, hijo de Ebana (Urk.IV: 4-5), y Ahmose Pennejbit (Urk.IV: 35). Asimismo, algunas inscripciones de esta época, como una estela de Masara fechada en el año 22 (Urk.IV: 25), parecen confirmar esta proyección.

18 Thutmés I concedió gran importancia a esta ciudad. Durante su gobierno se inauguró una interesante práctica político-militar: el príncipe heredero residió largas temporadas en Memfis para recibir instrucción militar y representar a la monarquía en el norte. Una clara muestra la tenemos en inscripciones que mencionan la presencia del príncipe heredero Amenmese en el norte (Urk.IV: 91 ).

19 Una inscripción hallada en la isla de Sehel parece indicar que la reina comando una expedición militar contra rebeldes del sur (L. HABACHI, Two Graffiti at Sehel from the Reign of Queen Hatshepsut. JNES 16 (1957): 88-104). 
del país del Nilo llegaría a su máxima expresión en tiempos de Thutmés III (1468-1436 a.C.). Nada más subir al poder en solitario, este monarca hubo de hacer frente a una gran coalición asiática acantonada en Megiddo, dirigida por el gobernante de Kadesch y auspiciada, probablemente, por la monarquía mitannia. Según las fuentes, el acierto estratégico del faraón permitió que Egipto lograra una extraordinaria victoria ${ }^{20}$. En el transcurso de los años siguientes se efectuaron hasta dieciseis operaciones de ampliación y consolidación de fronteras, destacando la sexta, que tuvo como consecuencia la conquista de Kadesch (Urk.IV: 689-90), y la octava, que cubrió el objetivo de cruzar el Éufrates, humillando al potente Estado mitannio ${ }^{21}$. Thutmés III no fue solamente un guerrero, sino que diseñó un programa de control permanente de los territorios ocupados a fin de buscar un alto rendimiento económico a bajo coste. Durante su gobierno el término «Imperio" alcanzaría su justa dimensión: en Asia, Egipto dominaría Palestina, Líbano y el sur de Siria, mientras que en África establecería la frontera al sur de la cuarta catarata. Mediante un sistema de gobernadores y pequeñas guarniciones que dejaban amplia autonomía a los príncipes y dirigentes locales, el faraón pretendía lograr dos objetivos prioritarios: el dominio de territoriosescudo que dificultaran una invasión externa como había acontecido en tiempos de los hicsos y la explotación económica de ricas zonas comerciales. $Y$ en este marco, el control sobre ciudades asiáticas con tradición metalúrgica contribuiría a la mejora técnica de algunas armas y a la introducción de innovaciones bélicas. Amenhotep II (ca. 1436-1412 a.C.), hijo del anterior, defendió los límites septentrionales del Imperio ante las acometidas de mitannios e intentos de sedición ${ }^{22}$.

20 La gran victoria de Megiddo fue ampliamente difundida por la propaganda faraónica. Se ha conservado información, en mejor o peor estado, en los anales de la campaña en el templo de Amun de Karnak (Urk.IV: 647-667), en la estela de Gebel Barkal (1234-36), en una estela del templo de Ptah de Karnak (Urk.IV: 766-67) y en una estela de Armant (Urk.IV: 124647).

${ }^{21}$ La octava campaña fue espectacular: las tropas egipcias trasladaron barcos sobre carros tirados por bueyes desde las inmediaciones de Biblos hasta la ribera del Éufrates. Allí cruzaron el río y auyentaron al ejército mitannio. Las repercusiones de esta acción fueron tan importantes como las de la victoria de Megiddo, y también se les dió amplia difusión. Las principales evidencias escritas, lamentablemente mal conservadas, aparecen en los anales de Karnak (Urk.IV: 696-99), una inscripción en el séptimo pilono de Karnak (Urk.IV: 188-89); la estela de Gebel Barkal (Urk.IV: 1231-33); la estela de Armant (Urk.IV: 1246) y un obelisco, sito actualmente en Constantinopla (Urk.IV: 586-87).

${ }_{22}$ Una buena síntesis sobre las campañas militares de este faraón se encuentra en $P$. der ManueliAn, Studies in the Reign of Amenophis II. HÄB 26 (1987). 
Durante esta fase, el ejército siguió combatiendo con armas tradicionales, como indica, por ejemplo, el pequeño arsenal de hojas de hacha y puñales hallado en la tumba de la reina Aahotep ${ }^{23}$, madre de Kamose y Ahmose, o como se puede ver en los desfiles militares esculpidos en el templo funerario de Hatschepsut en Deir el-Bahari (fig. 5), aunque iría incorporando paulatinamente nuevo armamento procedente de Asia. Están perfectamente documentados objetos bélicos cuyo uso se fue desarrollando en el transcurso de esta época. Entre los mismos cabe subrayar: carros de guerra ligeros tirados por dos caballos, arcos compuestos, espadas curvas, cascos y cotas. Asimismo, se observan mejoras técnicas en el bronce y una mayor utilización de este metal en la elaboración de puñales y espadas fundidos en una única pieza, así como en puntas de lanza o flecha.

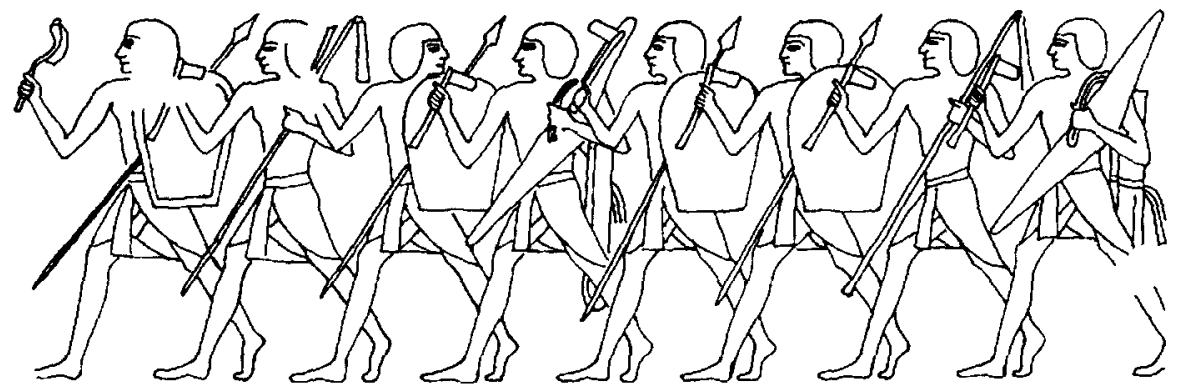

Figura 5. Integrantes de un desfile militar esculpido en las paredes del templo funerario de la reina Hatschepsut en Deir el-Bahari.

a) El carro de guerra tirado por dos caballos: Parece evidente que la introducción de estos vehículos en Egipto se debe a los hicsos. Tenemos documentado su uso por parte egipcia en tiempos de Ahmose, según destaca la biografía de Ahmose, hijo de Ebana (Urk.IV: 3), y podemos ver cabezas de caballos en fragmentos de relieves hallados en Abydos que han sido atribuidos al período Ahmose/Amenhotep ${ }^{24}$. Estos vehículos, que durante la época en cuestión poseian ruedas con cuatro radios, se convirtieron pronto en objetos de prestigio usados

23 La totalidad de las piezas que se hallaron en la tumba de la reina Aahotep se puede observar en el trabajo de F.W. VON BISSING (Ein thebanischer Grabfund aus dem Anfang des Neuen Reichs. Berlín, 1900).

24 S. HARVEY, The Monuments of Ahmose at Abydos. BEES 4 (1994): 3-5. 
por altos funcionarios en sus paseos, como se observa en relieves de las tumbas de Renni (fig. 6) o User, hombres que sirvieron respectivamente a Amenhotep I y Thutmés I ${ }^{25}$. En una tumba no identificada de

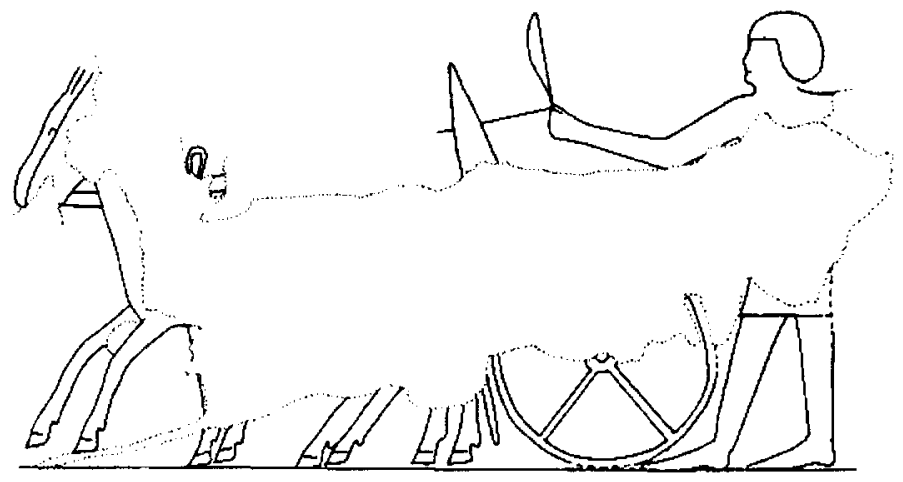

Figura 6. Fragmento de carro y caballos esculpidos en la tumba del funcionario Renni. EI-Kab. J.J. TYLOR/F.L. GRIFFITH, op. cit.: lám. II.

la necrópolis tebana fue hallado el armazón de un carro datable en este período (fig. 7). El vehículo, actualmente en el Museo de Florencia, presenta las siguientes medidas: plataforma de $97 \times 54 \mathrm{cmts}$; eje de ruedas de $198 \mathrm{cmts}$; altura de ruedas, que poseen cuatro radios, de $100 \mathrm{cmts}$, y longitud de la barra de enganche de $253 \mathrm{cmts}$.

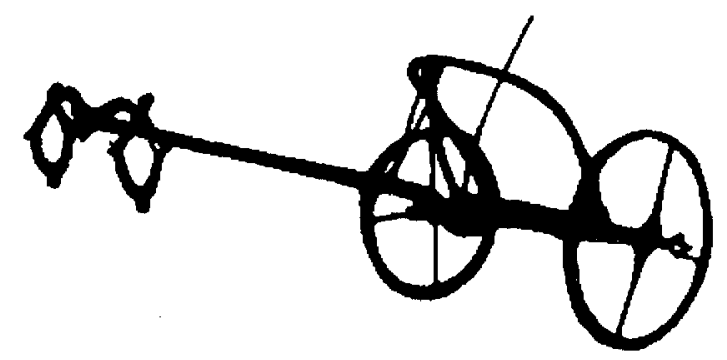

Figura 7. Armazón del carro expuesto en el Museo Arqueológico de Florencia. 2678.

25 La tumba de Renni, en El-Kab, fue publicada por J.J. TrLor/F.L GRIFFITH, The Tomb of Renni. Londres, 1900. Únicamente se conserva parte de una rueda del carro que figuraba en las paredes de la tumba de User (N. de G. Davies, Five Theban Tombs. Londres, 1913: lám. XXII). En este punto conviene subrayar que las pinturas y relieves parietales de muchas tumbas privadas de esta época constituyen una de las mejores fuentes para conocer el armamento. 
Los carros de guerra portaban una o dos largas cajas para guardar el armamento que era usado por sus dos tripulantes, el conductor y el portaescudo. El primero podía atarse las riendas a la cintura para utilizar el arco, como puede verse en un relieve de Amenhotep II hallado cerca del tercer pilono de Karnak (fig. 8), mientras que el segundo tenía una función protectora.

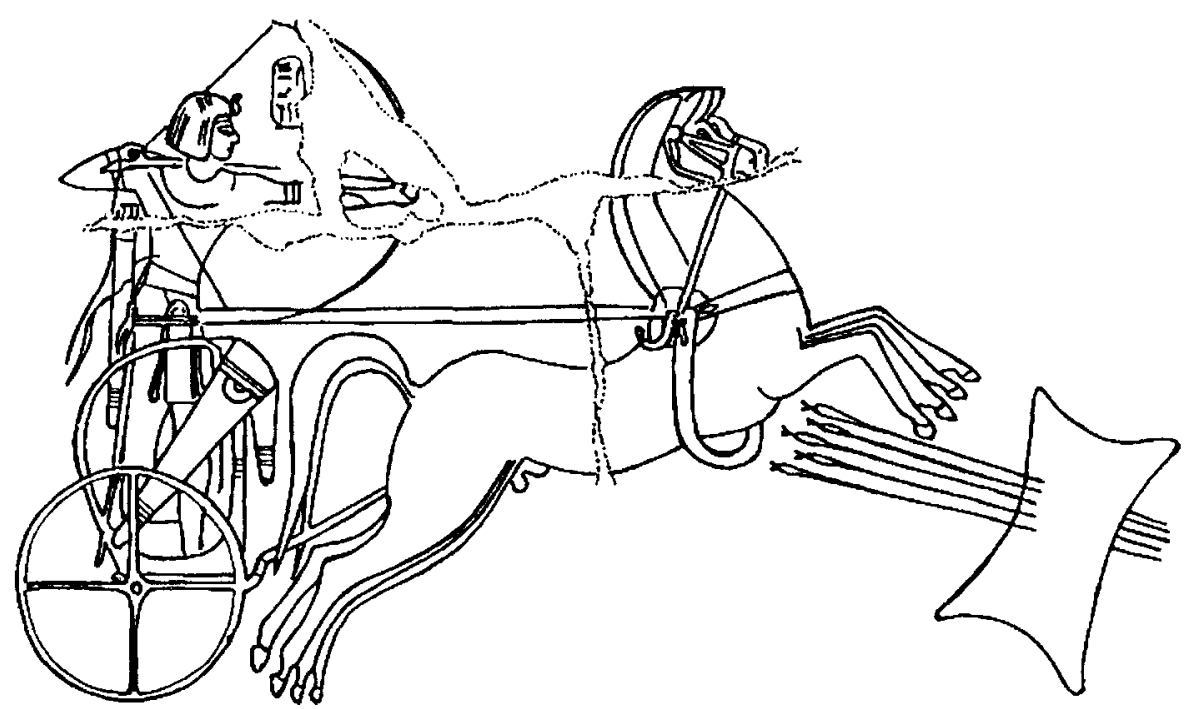

Figura 8. Amenhotep II practicando ejercicios castrenses: dispara flechas desde su carro contra planchas de cobre. Estela J.44 del Museo de Luxor.

El protagonismo de los carros de guerra egipcios ha sido generalmente exagerado ${ }^{26}$. No hay constancia de que el ejército faraónico, contrariamente a otras fuerzas armadas de la época, tuviera al carro de guerra como su piedra angular. De hecho, fue siempre la infantería el elemento principal de una batalla. $Y$ las razones son obvias: los infantes, encuadrados en compañías, eran embarcados con mayor facilidad hacia Nubia o Asia, y podían enfrentarse a libios y kuschitas en

${ }^{26}$ La idea de centenares o miles de carros egipcios marchando veloces contra el enemigo no tiene ningún fundamento sólido. En este sentido, el autor coincide con el planteamiento que en su día efectuó A.R. SchULmAN (Chariots, Chariotry and the Hyksos. JSSEA 10 (1979-80): 129-130). 
zonas poco propicias para el despliegue de carros ${ }^{27}$. En combate, estos vehículos eran usados esencialmente para hostigar al enemigo antes y después del choque.

Según los anales de Thutmés III, la victoria de Megiddo reportó la captura de un total de 924 carros de guerra asiáticos (Urk.IV: 664). Fuentes de su hijo, Amenhotep II, destacan que durante su campaña del año 7 fueron capturados 730 vehículos con todos sus accesorios (Urk.IV: 1305).

b) El arco compuesto: Aunque no se han encontrado evidencias de su uso por parte de los hicsos, es más que probable que fueran ellos quienes introdujeron este potente objeto en el país del Nilo. Estas armas, de probable origen acadio ${ }^{28}$ poseían formas curvadas o triangulares, según se observa en representaciones de la época (fig. 9), y

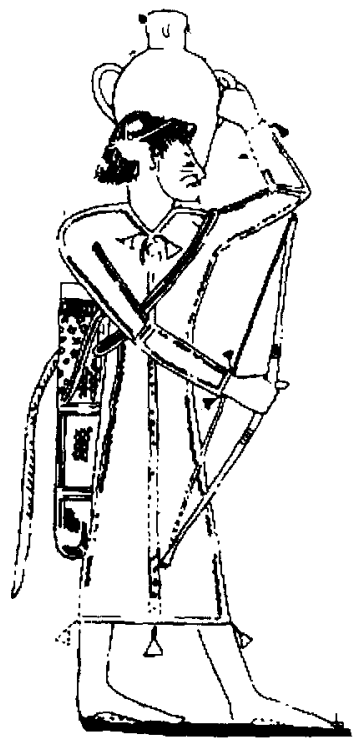

Figura 9. Tributario asiático que porta un arco compuesto con forma triangular. T.T. 100, perteneciente a Rejmire (N. de G. DAVIES, The Tomb of Rekh-mi-Re at Thebes. Nueva York, 1943: lám. XXI).

27 Se conservan suficientes evidencias como para afirmar que el ejército egipcio ya poseía unidades de infantería de marina.

28 BONNET, op. cit.: 135; YADIN, op. cit. Vol. I: 62-63. 
estaban formadas por una vara central de madera y varias tiras de asta de antílope o maderas de distintas clases, unidas con fibras vegetales y tendones de animales ${ }^{29}$. Esta composición proporcionaba una extraordinaria elasticidad y permitía lanzar flechas a gran distancia. La tumba de un oficial llamado Ahmose Pen-hat, que combatió bajo las órdenes de los primeros faraones de esta dinastia, brindó ocho fragmentos de dos arcos cuya longitud total debió ser de unos $125 \mathrm{cmts}^{30}$. El arco compuesto llegaría a ser muy útil para los soldados de los carros de guerra, y su progresiva implantación fomentaría la fabricación de flechas con punta metálica.

La importancia de este objeto bélico queda reflejada en los ya citados anales de Thutmés III sobre la batalla de Megiddo: el ejército egipcio se apoderó de 502 arcos de estas características (Urk.IV: 664).

c) La espada curva: Arma de origen elamita o mesopotámico cuyo uso simbólico, como objeto de poder, se extendió por Siria-Palestina durante la primera mitad del segundo milenio a.C. Hermosas espadas de parada con larga parte recta de la hoja seguida de una parte curva, casi semicircular, coronada por un uraeus o una flor de loto, fueron halladas en la necrópolis real de Biblos y en un depósito de armas de Sichem ${ }^{31}$. Los egipcios del Imperio Medio conocían su existencia, pues se encontró una espada curva de diseño similar, y con una flor de loto como adorno, en Abydos (fig. 10), pero no hay constancia de que las incorporaran a su simbología ni a sus arsenales. Tampoco tenemos evidencias sólidas sobre el uso militar de la espada curva por parte de los hicsos, aunque no podemos descartar que la utilizaran ${ }^{32}$. De hecho, debemos subrayar

29 Según las fuentes arqueológicas que se ha conservado, no habia una única directriz para el material usado en la elaboración de un arco compuesto. Una buena descripción de los arcos compuestos y sus distintas variantes se encuentra en W. MACLEOD (Egyptian Composite Bows in New York. AJA 66 (1962): 13-21). El citado trabajo de este investigador sobre los arcos hallados en la tumba de Tutanjamun es también un buen complemento.

30 W.C. HAYES, The Scepter of Egypt. Vol. II. Nueva York, 1959: 211; W. MACLEOD, 1962; 16-17.

31 Una buena descripción sobre este tipo de piezas se puede encontrar en MÜLLER (op. cit.: 117-127).

32 Müller (op. cit.: 131-132) sostiene que una espada curva fundida en una pieza de bronce y hallada presuntamente en Kantir (así lo manifestó quién la encontró y vendió) podría pertenecer al ámbito cultural hicso. Para ello argumenta que esta pieza presenta, en la hoja, una serie de espirale similares a la decoración de las antiguas espadas halladas en Biblos. Sin embargo, no ve relación entre este arma y la empuñadura de una espada curva que porta los cartuchos reales de Seti I y decoración espiral muy parecida. Dicho de otra manera, no tenemos evidencias sólidas sobre el posibłe origen hicso de esta pieza. Además, entre el 


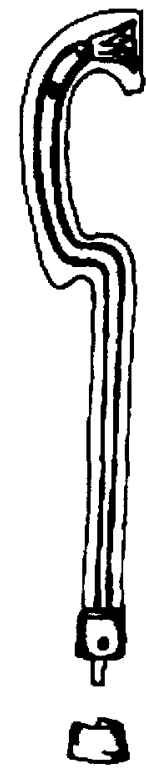

Figura 10. Espada curva (47 cmts de longitud) parecida a las antiguas formas halladas en Biblos y Sichem. Encontrada en Abydos, aunque se han perdido referencias. Ontario Museum, Toronto. Dibujo copiado a partir de un dibujo que aparece en la obra de MÜLLER (op. cit.: 119, fig. 37-10).

que estas armas eran básicamente simbólicas y con poca efectividad real en el campo de batalla. Sin embargo, a mediados del siglo xvI a.C. cuando en el Próximo Oriente se extendió la elaboración de puñales y espadas fundidos en una sola pieza de bronce, comenzaría la fabricación de espadas curvas, con parte curva más suavizada y larga, destinadas a la guerra. En lo que refiere a Egipto, pruebas feacientes de espadas curvas como elementos de combate no aparecen hasta el gobierno de Thutmés III ${ }^{33}$, según demuestran los anales del

abundante armamento asiático hallado en Tell el-Dab'a únicamente se ha encontrado una espada curva con hoja de $40 \mathrm{~cm}$ parecida a las de Biblos, Sichem y Abydos, pero con punta en espiral. Evidentemente se trata de un arma de parada. (I. Forstner-Müller, "Vorbericht der Grabung im areal A/II in Tell el-Dab'a". Ägypten und Levante XI (2001):197-220). En consecuencia, no existe hoy en día ninguna prueba fundamentada sobre uso generalizado de la espada curva por parte de los hicsos.

${ }^{33}$ En los desfiles militares esculpidos en las paredes de Deir el-Bahari (ver en fig. 5) se puede distinguir un oficial que porta una extraña espada curva parecida a los antiguos modelos. El hecho de que aparezca solamente un militar con un objeto semejante y muchos sol- 
año 41 que reflejan el envío de armas de este tipo desde Retenu (URK.IV:726) o las pinturas de la T.T. 86, perteneciente al funcionario Menjeperresoneb, que presentan tributarios asiáticos con semejantes objetos (fig. 11-a). Las evidencias aumentan en tiempos de Amenhotep II, como se observa en pinturas de las paredes de las T.T. 100 y 93, pertenecientes respectivamente al visir Rejmire (fig. 11-b) y al funcionario Kenamun (fig. 11-c), o en el fragmento de un gran relieve, hallado entre los pilonos tercero y cuarto de Karnak, que muestra una interesante escena ${ }^{34}$ : Amenhotep II en ademán de golpear con una espada curva a los enemigos asiáticos. La iconografía de masacre o sacrificio de enemigos se remonta al período predinástico ${ }^{35}$, pero la citada escena es la más antigua, hasta hoy conocida, de una espada curva en manos de un faraón.
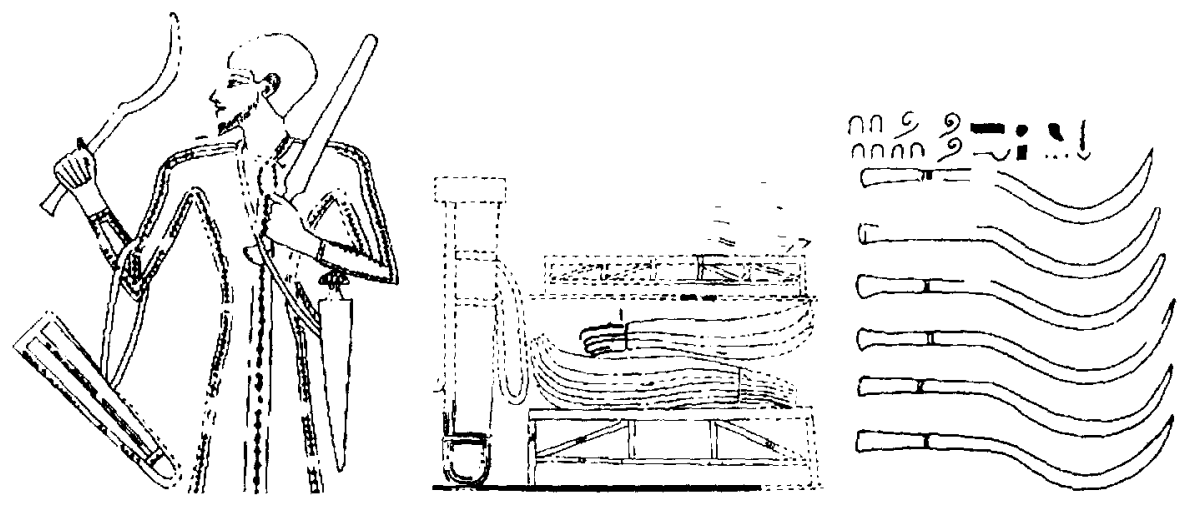

Figura 11. Espadas curvas pintadas en tumbas tebanas. A: Tributario asiático con espada curva. T.T. 86 (N. de G. DAVIES, The Tombs of Menkheperresoneb, Amenmose and another. Nos. 86, 112, 42, 226. Londres, 1933: lám. V). B: Espadas curvas almacenadas. T.T. 100 ( $N$. de G. DAVIES, 1943: lám. XXXVII). C: Espadas curvas almacenadas. T.T. 93, perteneciente a Kenamun ( $N$. de G. DAVIES, The Tomb of KenAmun at Thebes. Nueva York, 1930: lám. XX).

dados porten hachas demuestra que la espada curva no era usual. En representaciones del periodo amarniense (ver en fig. 25) son más frecuentes los guerreros armados con estas espadas. Estos datos parecen indicar que la implantación se produjo en la época que va del gobierno de Hatschepsut al de Ajenatón.

${ }^{34}$ Este bloque forma parte de una gran escena que ilustra una acción punitiva contra asiáticos rebeldes (A.H. ZAYED, Une représentation inédite des campagnes d'Aménophis II. BdE 97 (1985): 5-17).

${ }_{35}$ Una buena sintesis sobre las escenas de mascacre o sacrificio de enemigos fue escrita por E.S. HALL, The Pharaoh Smites His Enemies. MÄS 44 (1986). 
d) Cascos y cotas: No han sido halladas evidencias claras sobre el uso de cascos o cotas antes del reinado de Thutmés III. En representaciones de algunas tumbas privadas de la época Thutmés III/Amenhotep II, como las citadas de Menjeperresoneb, Rejmire y Kenamun, sepueden observar cascos coniformes, ocasionalmente con plumas, portados por tributarios asiáticos o almacenados (fig. 12-a/b/c). Asimismo, los anales del año 35 de Thutmés III mencionan cinco cascos de bronce como parte del botín de una operación en Asia (Urk.IV: 712).
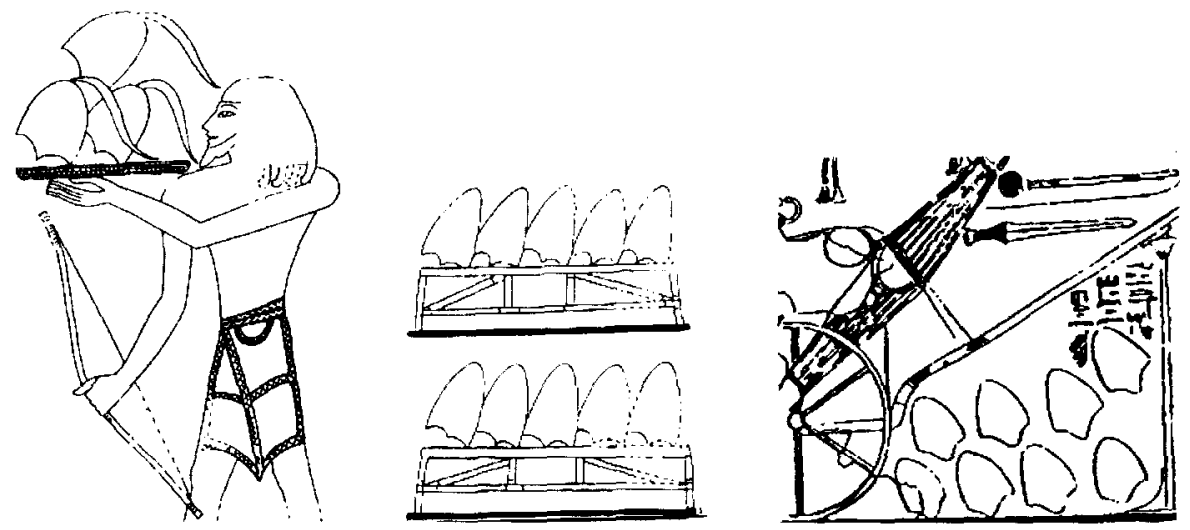

Figura 12. Cascos pintados en tumbas tebanas. A: Tributario asiatico con bandeja de cascos. Tumba de Menjeperresoneb ( $N$. de G. DAVIES, 1933: lám. V.). B: Cascos almacenados. Tumba de Rejmire ( $N$. de G. DAVIES, 1943: lám. XXXVII). C: Cascos almacenados. Tumba de Kenamun (N. de G. Davies, 1930: lám. XX).

La utilización de cotas también está documentada por primera vez bajo los gobiernos de estos faraones. En las paredes de la tumba de Kenamun se pueden observar cotas que presentan las siguientes características: lámina protectora en el cuello y prenda forrada con placas de bronce que presentan un refuerzo central (fig. 13-a).

En niveles de la ciudad asiática de Nuzi, datables en este período, fueron halladas placas de bronce, de tres tamaños distintos, que presentaban orificios para ser cosidas a una tela ${ }^{36}$. Este tipo de protección cubría la totalidad del cuerpo y la parte superior de las piernas. La mencionada lista de botín de Megiddo incluye la incautación de 200 cotas a los vencidos, y

36 Y. YADIN, op. cit. Vol. I: 196. 

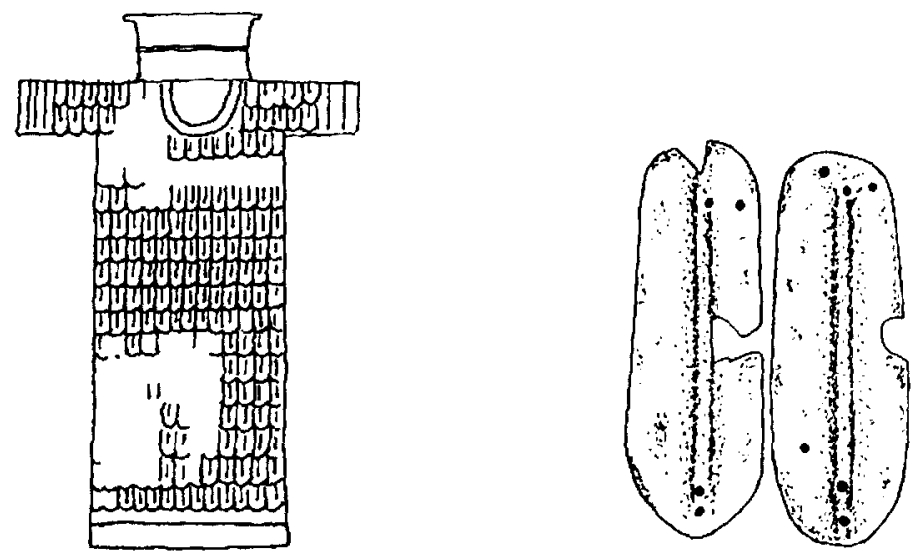

Figura 13. A: Cota metálica pintada en la pared de la tumba de Kenamun (N. de G. DAVIES, 1930: lám. XXII). B: Láminas metálicas (11 cmts), con refuerzo central y orificios, pertenecientes a una cota hallada en el palacio de Malkata. Dibujo copiado a partir de foto en WINLOCK (op. cit:: lám. 29).

los anales del año 40 reflejan la llegada a Egipto de una cota con engarces de oro y un número indeterminado de cotas de bronce (Urk.IV: 670). En base a lo expuesto, podemos destacar que durante la primera mitad del siglo XV a.C. el ejército egipcio comenzó a usar protecciones corporales procedentes, originariamente, de la zona de Siria-Palestina. Este dato no significa que se produjera un uso masivo: el considerable peso de las cotas las habilitaba para el combate desde un carro de guerra, pero no eran prácticas para un infante.

Los puñales y espadas fundidos en una pieza de bronce, cuyas primeras evidencias en Egipto aparecen a finales del periodo hicso, también contribuyeron a mejorar notablemente los arsenales egipcios. Estos objetos bélicos poseían las siguientes características: hoja de doble filo, ocasionalmente con nervatura o refuerzo central; guardamanos corto; empuñadura hueca, cubierta por una placa de madera o marfil a cada lado, y pomo, generalmente semicircular ${ }^{37}$. Han sido halladas diversas piezas de bella factura, entre las que se pueden destacar una

37 Se han encontrado pocas piezas de estas características y, por lo tanto, no son citadas en demasiadas publicaciones. Al margen de las alusiones a las mismas que hace la bibliografía general, podemos destacar los siguientes artículos: G.A. WAINWRiGHT, A Dagger of the Early New Kingdom. ASAE 25 (1925): 135-143; F. PETRIE, Daggers with inlaid Handles. AE 4 (1930): $97-102$. 
espada corta (fig. 14-a) y un puñal dedicado por Thutmés III al célebre general Djehuty (fig. 14-b), mítico héroe de la conquista de Joppa.
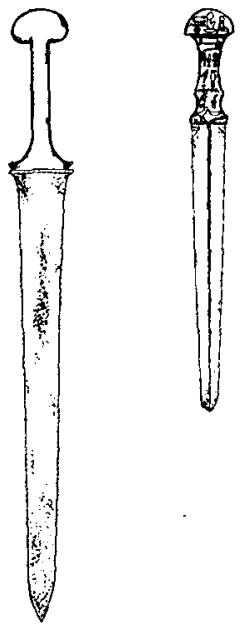

Figura 14. Espada y puñal fundidos en una pieza de bronce. A: Espada de $52 \mathrm{cmts}$ de longitud hallada en la necrópolis tebana. Museo Metropolitano de Nueva York. B: Puñal de 33,6 cmts que porta el nombre del general Djehuty en la empuñadura. Museo de Darmstadt. Piezas copiadas a partir de los dibujos de PETRIE (1930).

Durante esta época aumentó notablemente el uso de puntas de bronce, tanto para flechas como para venablos. Una muestra la tenemos en la tumba de Nefer-jeuet, funcionario de Thutmés III que legó a la arqueologia hasta siete puntas de flecha romboidales que miden entre 7 y 10 $\mathrm{cmts}^{38}$. También han sido encontradas numerosas puntas de flecha romboidales o palmiformes, con largos pedúnculos, en tumbas de necrópolis nubias ${ }^{39}$. En lo que refiere a venablos, cabe subrayar una cuestión de especial interés; entre los diversos objetos bélicos que formaban parte del ajuar del famoso Senmut había venablos que presentaban, en su extremo posterior, bolas de marfil o ébano que ayudaban a su estabilidad, una vez lanzados ${ }^{40}$. Esta característica aparece con frecuencia en los relieves militares ramésidas.

38 W.C. HAYES, The Egyptian Expedition. Suplemento del BMMA (Noviembre 1935): 32.

39 T. SÄve-Söderbergh, New Kingdom Pharaonic Sites. The Finds and Sites. Uppsala, 1991: 172-174. Esta obra contiene fotos de muchas de estas puntas, asi como de hojas de hacha y puñales fundidos en una pieza de bronce que fueron hallados en distintas tumbas.

40 W.C. HAYES, 1959: 212. 
El poder de destrucción de una punta de bronce perteneciente a una flecha o a un venablo queda ilustrado con un macabro descubrimiento en la tumba de una necrópolis de Dakka, a unos $100 \mathrm{kmts}$ al sur de Assuan: un cadáver mostraba una de sus vértebras cervicales atravesada por un objeto de estas particularidades ${ }^{41}$ (fig. 15).

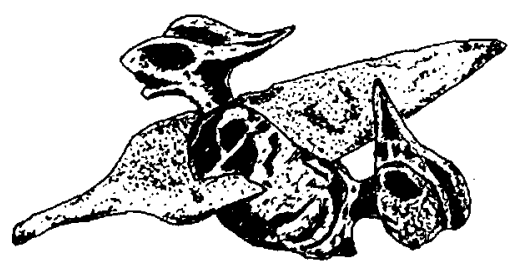

Figura 15. Punta de flecha, atravesando una vértebra cervical, hallada en una tumba de una necrópolis de Dakka. Hunterian Museum of the Royal College of Surgeons of England. Dibujo a partir de una foto en NUNN (op. cit.: fig. 8.10).

Los egipcios tenían tres sistemas de suministro de armamento: los cuantiosos botines de guerra, los ya mencionados tributos asiáticos que cada año llegaban a Egipto, o la elaboración propia de objetos bélicos (fig. 16).

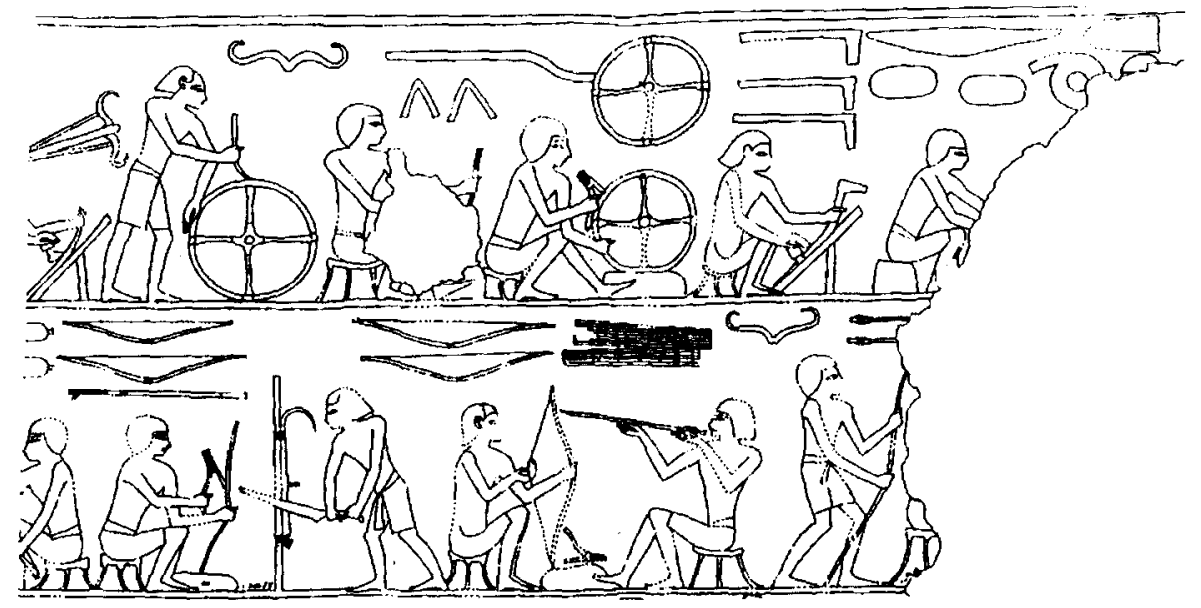

Figura 16. Artesanos fabricando carros, arcos y flechas. Tumba de Menjeperresoneb (N. de G. DAvies, 1933: lám. XII).

41 J.F. Nunn, Ancient Egyptian Medicine. Londres, 1996: 180-181, fig. 8.10. 


\section{SEGUNDA FASE DE LA DINASTIA XVIII (THUTMÉS IV-HOREMHEB): MANTENIMIENTO Y MEJORAS DEL ARMAMENTO INCORPORADO.}

Desde el punto de vista histórico esta época está caracterizada por la firma de la paz entre egipcios y mitannios durante el gobierno de Thutmés IV (ca. 1412-1402 a.C.), el brillante gobierno de Amenhotep III (ca. 14021364 a.C.), enturbiado en su tramo final por las maniobras del amorrita Abdi-Aschirta y la irrupción del hitita Suppiluliuma; los cambios político-religiosos promovidos por Ajenatón (ca. 1364-1347 a.C.) y la pérdida de territorios asiáticos ante los hititas ${ }^{42}$, el caótico período post-amarniense, con Tutanjamun (ca. 1347-1338 a.C.) y Ay (ca. $1337-1333$ a.C.), y la restauración interna, manu militari, protagonizada por Horemheb (ca. 13331306 a.C.). Durante esta fase el ejército sería reformado; el arma de carros de guerra formaría un cuerpo aparte, con administración y jerarquía propias, y se produciría una numerosa incorporación de mercenarios y auxiliares asiáticos y libios ${ }^{43}$. Desde el punto de vista armamentístico, debemos subrayar que los objetos bélicos encontrados en la tumba de Tutanjamun dan una amplia visión de la panoplia egipcia de aquel momento ${ }^{44}$ : 6 carros, con una longitud de la vara de enganche que oscila entre 243 y $260 \mathrm{cmts}$ (fig. 17); 14 arcos simples y 29 arcos compuestos de distintas longitudes (fig. 18); 327 flechas, con una longitud media de la caña o vara de unos $85 \mathrm{cmts}$ y con puntas de bronce, madera, marfil, hueso o cristal (fig. 19); 8 escudos, de los cuales 4 eran de madera forrada con piel de animal; 2 espadas curvas (fig. 20-a/b), armas cuyo uso se extendió notablemente en esta época según muestran numerosos relieves (ver en fig. 23); 2 puñales (fig. 21); numerosos bastones y una cota

42 La figura poética de este monarca se ha ido desmoronando a medida que se han encontrado bloques pétreos con escenas de masacre protagonizadas por el rey (ver, por ejemplo, en HALL, op. cit.: figs. 37-40) o que se ha constatado la brutalidad empleada por su ejército contra bandas nubias, según se puede leer en textos de Buhen y Amada (W. HELCK, Ein "Feldzug" unter Amenophis IV. gegen Nubien. SAK 8 (1980): 117-126).

43 La escisión del arma de carros en esta época se observa en la aparición de rangos nuevos, tanto civiles como militares. Amplia información sobre esta circunstancia se encuentra en R.O. FAULKNER, Egyptian Military Organization. JEA 39 (1953): 32-47; A.R. SCHULMAN, Military Rank, Title and Organization in the Egyptian New Kingdom. MÄS 6 (1964): 14-15; A.M. GNIRS, Militär und Gesellschaft: Ein Beitrag zur Sozialgeschichte des Neuen Reiches. SAGA 17. Heidelberg, 1996: 17-18. En cuanto a la incorporación de mercenarios extranjeros, cabe mirar los numerosos soldados foráneos representados en tumbas de El-Amarna.

44 El numeroso armamento hallado en la tumba de Tutanjamun es citado, con mayor o menor descripción, en los volúmenes II y III de la obra de H. CARTER, The Tomb of Tut-ankh-Amen. Londres/Toronto/Meibourne/Sydney, 1927 (vol. II) y 1933 (vol. III). Asimismo, debemos recordar ios ya citados trabajos de MACLEOD sobre arcos y flechas, y LITTAUER/COUWELL Sobre carros. 


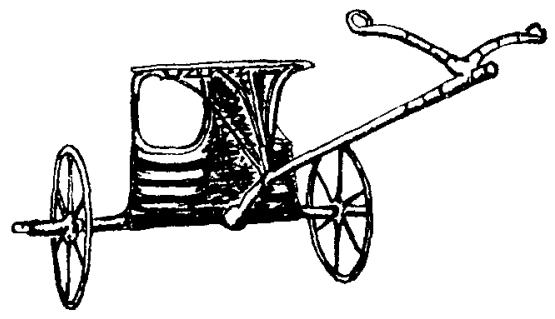

Figura 17. Carro hallado en la tumba de Tutanjamun. Museo Egipcio del Cairo, nr. de referencia 122. Dibujo copiado a partir de foto en LITTAUER/CROUWEL, op. cit.: lám. XIII.

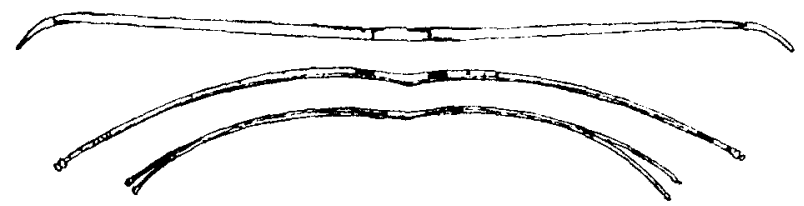

Figura 18. Dos arcos compuestos y uno simple hallados en la tumba de Tutanjamun. Museo Egipcio del Cairo. Dibujo copiado a partir de foto en MACLEOD, 1970: lám. III.

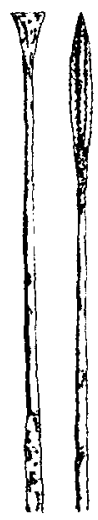

Figura 19. Flechas halladas en la tumba de Tutanjamun. Museo Egipcio del Cairo. Dibujo copiado a partir de foto en MACLEOD, 1982 . lám. IV.
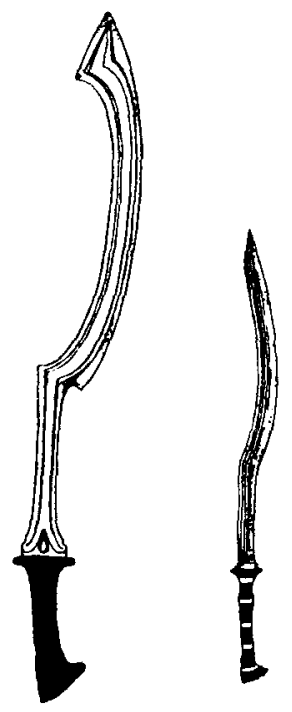

Figura 20 Dos espadas Figura 21. Puñal de hierro curvas $(59 \mathrm{cmts} / 40 \mathrm{cmts})(34,2 \mathrm{cmts})$ hallado entre los halladas en la tumba de vendajes de la momia de Tutanjamun. Museo Egipcio Tutanjamun. Museo Egipcio del Cairo. Dibujo copiado a partir de fotos en CARTER, del Cairo. op. cit.: lám. XLV. 
con placas de cuero endurecido. Como armas de uso común, únicamente faltan hachas y venablos.

Esta visión del armamento se completa con instrumentos bélicos hallados en otros ámbitos arqueológicos y datados en tiempos de otros monarcas. Así, podemos destacar las siguientes piezas: las placas de bronce, con refuerzo central y perforaciones para pasar el hilo que las sujetaba a una pieza de tela, pertenecientes a una cota hallada en los cimientos del palacio de Amenhotep III en Malkata (fig. 13-b) o las hojas de hacha y puntas de venablo palmiformes encontradas en Tell el-Amarna (fig. 22-a/b). El armamento mencionado coincide con los objetos bélicos que aparecen en las numerosas representaciones militares del arte amarniense (fig. 23).
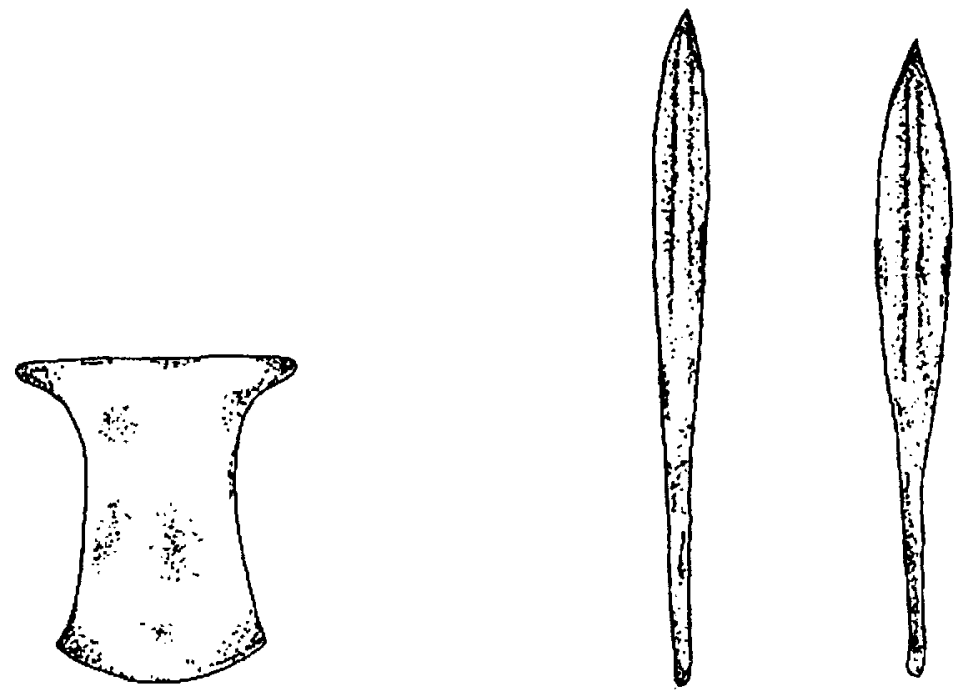

Figura 22. Hoja de hacha (11, $7 \mathrm{cmts})$ y puntas de venablo $(15,7$ y 14,7 cmts) hallados en Tell el-Amarna. Museo Egipcio de Berlín. Dibujos a partir de fotos en Wolf (op. cit:: lám. $11, n r .5$ y lám. IX, nrs. 15 y 16).

Si bien no se observa la llegada a Egipto de armamento nuevo, si conviene subrayar las modificaciones que se produjeron, a lo largo de este período, en los siguientes objetos bélicos:

- Carros de guerra: Según se observa en obras artísticas, en tiempos de Thutmés IV se dobló el número de radios de los carros, 


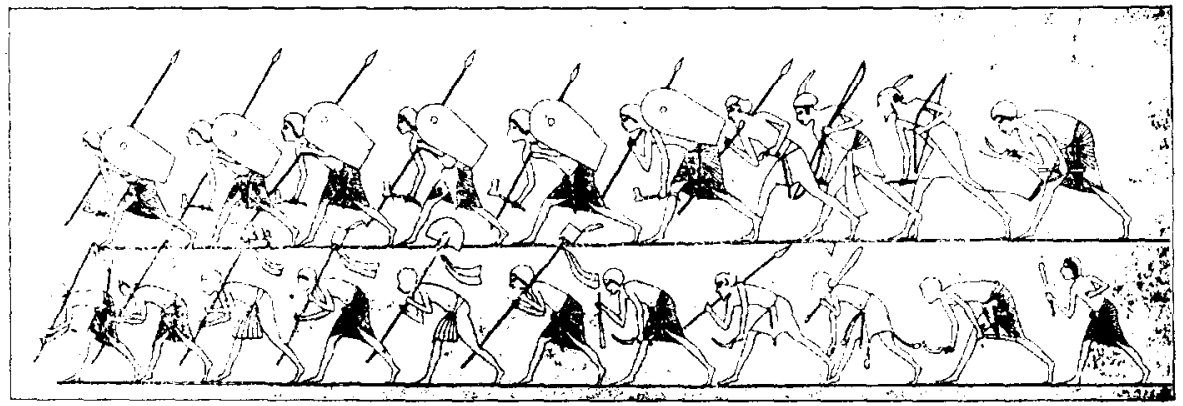

Figura 23. Soldados de la guardia de Ajenatón con armamento de su época. Tumba de Ahmose en Tell el-Amarna ( $N$. de G. DAVIES, The Rock Tombs of El Amarna. Vol. III. Londres, 1903-1906: lám. XXXI).

con el probable fin de aumentar su estabilidad. (fig. 24) Durante el gobierno de Amenhotep III, el número de radios quedó fijado en seis, y así permanecería hasta finales del Imperio Nuevo (ver, por ejemplo, en fig. 17).

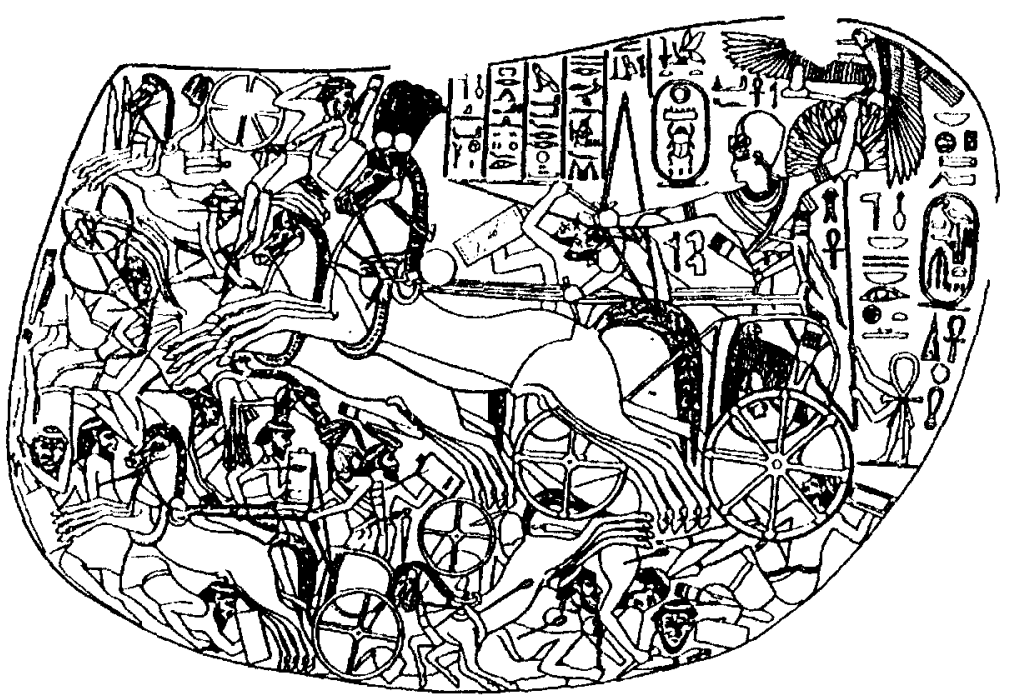

Figura 24 El faraón Thutmés IV masacrando a enemigos asiáticos desde un carro de guerra con ruedas de ocho radios. Parte externa del panel derecho del carro hallado en la tumba de este monarca. Museo egipcio del Cairo. (H. CARTER/P. NEWBERRY, The Tomb of Thoutmosis IV. Westminster, 1904: lám. X. 
- Escudos: También en tiempos de Thutmés IV se observan por primera vez algunas modificaciones en los escudos. Estas protecciones son más largas que en tiempos anteriores; presentan una forma curvada que permite al soldado colocarse la pieza a la espalda con mayor comodidad (fig. 25), y algunas presentan un orificio en su parte superior mediante el cual el guerrero podía mirar con la cabeza protegida (ver en fig. 23).

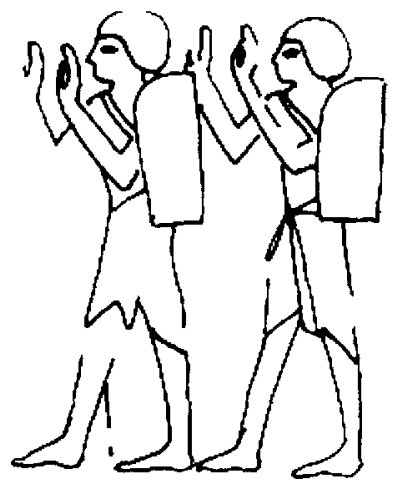

Figura 25. Soldados con escudos colgados en la espalda. Pared de la T.T. 90, perteneciente al comandante de policia, Nebamun ( $N$. de G. DAviES, The Tombs of Two Officials of Thutmosis the Fourth (Nos 75 and 90). Londres, 1923: lám. XXVII).

- Espadas curvas: Según los relieves, se produjo una notable extensión de su uso, aunque nunca sobrepasarian en importancia al hacha de guerra. Las dos únicas piezas pertenecientes a la dinastía XVIII que no presentan dificultades de datación fueron encontradas en la tumba de Tutanjamun. Una de las mismas mide $59 \mathrm{cmts}$ y presenta las características típicas de una espada curva fundida en una pieza de bronce: parte recta de la hoja corta y larga parte curva con final romo (fig. 20-a). Este prototipo ha aparecido en distintos puntos del Próximo Oriente ${ }^{45}$. Sin embargo, la otra, más pequeña, presenta una manifiesta originalidad: apenas mide $40 \mathrm{cmts}$ y tiene una suave curvatura que termina en punta afilada (fig. 20-b). Evidentemente, mientras que la primera servía para golpear al enemigo como si fuera un hacha,

45 H.W. MülleR (op. cit. 149-163) realizó un estudio de las espadas curvas halladas en la tumba de este rey y posibles paralelos asiáticos. 
con la segunda, genuínamente egipcia, se podia atravesar un cuerpo como si de un puñal se tratara ${ }^{46}$.

Durante esta época comenzó, aunque de manera restringida, la utilización de armas de hierro. Algunas cartas de los archivos de Tell elAmarna incluyen detalles sobre la llegada a la corte egipcia de puñales del citado metal procedentes del Estado mitannio ${ }^{47}$. Y la arqueología avala esta información: en el mencionado palacio de Malkata fue encontrada una punta de venablo de hierro ${ }^{48}$ y entre los vendajes de la momia de Tutanjamun apareció un hermoso puñal con hoja de este metal $^{49}$ (fig. 21).

\section{CONCLUSIONES}

Le evolución del armamento en Egipto estuvo siempre relacionada directamente con la situación geopolítica del país del Nilo. Mientras la monarquía faraónica no tuvo necesidad de contar con unas potentes fuerzas armadas, debido a cuestiones de aislamiento geográfico y de debilidad de enemigos potenciales, apenas prestó interés a la modernización armamentística. Aún así, no podemos tomar este argumento como determinante a la hora de explicar la invasión hicsa, puesto que, probablemente, los asiáticos conquistaron el delta con un armamento que no difería, en cuanto a efectividad, demasiado del egipcio. Las razones sobre el hundimiento político de la administración del país del Nilo durante el Segundo Período Intermedio hay que buscarlas en las crisis políticas y los intentos de secesión. Paradójicamente, a finales de esta época, cuando tenemos plenamente documentada una supremacía bélica hicsa sobre los tebanos, éstos lograron importantes victorias. La explicación a esta curiosa circunstancia histórica radica en el hecho de que para los tebanos fue más fácil llevar la guerra, con acciones rápidas,

46 H. CARTER (op. cit.: 137) consideró que esta pieza correspondía a un niño, sin tener en cuenta las diferencias con la espada más grande.

47 A. LuCAS, op. cit.: 240.

48 Algunas reflexiones sobre posibles armas de hierro de esta época, e incluso anteriores, se encuentran en A. LucAs (op. cit.: 235-243).

49 Si bien LUCAS aporta información sobre este puñal, cabe subrayar también la interesante aportación técnica de F.M. HELMI/K. BARAKAT (Micro Analysis of Tutankhamun's Dagger. Páginas 287-288 en Procedings of the First International Conference on Ancient Egyptian Mining \& Metallurgy and Conservation of Metallic Artifacs. Cairo (1995)). 
al río o a los desiertos, donde la tecnología superior del enemigo quedaba neutralizada, que intentar la incorporación de objetos bélicos nuevos. Poco efectivos eran los carros y los caballos en las aguas o en las arenas, y nada podian hacer ejércitos armados con arcos compuestos y espadas fundidas en una pieza de bronce frente a un enemigo que poseía una imponente flota fluvial que se movía con gran celeridad. Este sistema permitió que Sequenere y Kamose lograran ocupar casi la totalidad del Egipto central y los oasis occidentales, al tiempo que, indudablemente, capturaban nuevo armamento, el cual sería necesario para los grandes combates, ante las ciudades hicsas de Memfis, Heliópolis y Avaris, que llevaría a término Ahmose, el fundador de la dinastía XVIII. Dicho de otra manera, el ejército egipcio utilizó nuevo armamento cuando tuvo que enfrentarse en batalla abierta contra los hicsos.

La política de expansión hacia grandes zonas del Próximo Oriente asiático y Kusch, iniciada por Ahmose, y continuada por algunos de sus sucesores, no hubiera podido ser factible sin un ejército profesional armado convenientemente. Aún así, Egipto, que había incorporado a sus huestes el carro, el arco compuesto y modernos puñales y espadas, dedicó más esfuerzos al desarrollo de estrategias de combate que a la búsqueda de armas nuevas. Esto se observa con claridad en las fuentes que detallan el enfrentamiento de Megiddo. Dejando al margen la propaganda faraónica, parece evidente que las fuerzas asiáticas contaban con grandes unidades de carros tirados por caballos y que, como mínimo, dos centenares de sus guerreros portaban cotas. No hay constancia de que los egipcios ya usaran semejantes protecciones, con lo cual podemos concluir que, en líneas generales, el ejército asiático estaba mejor armado que el egipcio. Ahora bien, el mando faraónico supo sacar gran ventaja estratégica: sus huestes alcanzaron las inmediaciones de Megiddo tras cruzar el estrecho paso de Aruna. La apuesta era arriesgada, pues una encerrona en aquel punto hubiera podido terminar en desastre. Pero había un detalle a tener en cuenta: buena parte del ejército asiático estaba formada por carros de guerra y, evidentemente, estos vehículos no podían protagonizar una emboscada en una zona escarpada. Según las fuentes egipcias, las unidades de carros asiáticas se habían acantonado a lo largo de otras dos rutas que conducían a Megiddo. La sorpresa tendría continuidad cuando, al alba del día siguiente, el ejército faraónico se dividió en tres grandes unidades que obligaron a huir despavoridos a los asiáticos que estaban en un campamento cercano a la plaza fuerte. 
La victoria de Megiddo fue básica para la creación del gran imperio thutmósida y, desde el punto de vista armamentístico, también alcanzaría gran importancia. El control sobre ricas ciudades comerciales con larga tradición metalúrgica fue clave para conseguir una adecuada renovación del ejército y, por lo tanto, de sus armas. Pronto llegarían al país del Nilo importantes cantidades de armamento moderno: aumentó el número de carros, de espadas curvas, de puñales o espadas fundidos en una pieza de bronce y de puntas metálicas para armas arrojadizas, al tiempo que se introdujeron los primeros cascos y cotas. A pesar de estas innovaciones, buena parte de los soldados egipcios seguiría utilizando el armamento clásico.

La paz firmada con los mitannios en tiempos de Thutmés IV puso fin a un ciclo de guerras y abrió una fase, que duraría casi dos generaciones, de calma y prosperidad. Durante este período se efectuaron reformas en el ejército y pruebas para mejorar algunos objetos bélicos, como los carros, los escudos o una variante de espada curva. $Y$ de la mano de los antiguos enemigos asiáticos llegarian al país del Nilo algunas armas de hierro, metal de lujo que todavía tardaría algunos siglos en ser usado masivamente. 